\title{
Effect of milk feeding level on development of feeding behavior in dairy calves
}

\author{
E. K. Miller-Cushon, ${ }^{*}$ R. Bergeron, $†$ K. E. Leslie, $\ddagger$ and T. J. DeVries ${ }^{* 1}$ \\ *Department of Animal and Poultry Science, University of Guelph, Kemptville Campus, 830 Prescott Street, Kemptville, ON, K0G 1J0, Canada \\ †Department of Animal and Poultry Science, Campus d'Alfred, University of Guelph, Alfred, ON, K0B 1A0, Canada \\ ‡Department of Population Medicine, Ontario Veterinary College, University of Guelph, Guelph, ON, N1G 2W1, Canada
}

\section{ABSTRACT}

Evidence exists that early life experiences may influence development of characteristic feeding patterns in dairy cattle. The objective of this study was to determine the effect of milk feeding level on performance and development of feeding patterns in dairy calves. Twenty Holstein bull calves were assigned at birth to a milk replacer feeding level, fed via a teat: (1) ad libitum (ADL) or (2) restricted feeding at $5 \mathrm{~L} / \mathrm{d}(0.75 \mathrm{~kg}$ of milk replacer) in 2 feedings/d (RES). All calves were offered concentrate ad libitum during the milk feeding stage. Calves were weaned gradually during wk 7 and then fed a pelleted diet ad libitum for $7 \mathrm{wk}$. Calves were weighed 2 times/wk. Feed and milk intakes were recorded daily. Feeding behavior was recorded from video for $5 \mathrm{~d}$ in each of wk $3,6,8,11$, and 14. Calves fed ADL consumed 2.6 times more milk, had greater weight gain $(1.2$ vs. $0.6 \mathrm{~kg} / \mathrm{d})$, and consumed less solid feed $(45.2$ vs. $98.0 \mathrm{~g} / \mathrm{d}$ ) during the milk feeding period than did calves fed RES. As expected, providing milk ADL resulted in more frequent meals (in wk 6, 7.1 vs. 2.0) and more evenly distributed diurnal patterns of feeding activity compared with the RES milk level. When considering all sucking bouts (milk feeding and nonnutritive sucking), no difference was observed between treatments in daily bout frequency or sucking time/ bout. Postweaning, calves fed RES had initially greater rate of intake (24.9 vs. $17.8 \mathrm{~g} / \mathrm{min}$ ) and meal size (160.8 vs. $117.2 \mathrm{~g} / \mathrm{meal}$ ). Diurnal feeding patterns also differed in the first week after weaning, with ADL calves feeding less continuously at the time of feed delivery. Meal characteristics and diurnal patterns of feeding activity were similar between calves by the end of the trial. However, milk feeding level had a longer-term effect on variability in feeding behavior, with calves fed RES having greater day-to-day variability in feeding time and meal size. Variability of meal characteristics also

Received July 13, 2012.

Accepted September 26, 2012.

${ }^{1}$ Corresponding author: tdevries@uoguelph.ca decreased over time across treatments. These results suggest that milk feeding level may have a short-term influence on postweaning feeding behavior. However, differences in early feeding patterns due to milk feeding level do not appear to affect longer-term development of feeding patterns.

Key words: dairy calf, feeding behavior, learning

\section{INTRODUCTION}

Feeding patterns of dairy cattle are influenced by several external management factors (Albright, 1993), including time of feed delivery (DeVries et al., 2005) and competition in the environment (Friend and Polan, 1974). The influence of external factors on meal characteristics is of interest due to the interactions between feeding behavior, health, and welfare. For example, feeding patterns characterized by large, infrequent meals are associated with the incidence of SARA (Krause and Oetzel, 2006). Although management factors influence feeding patterns at a herd level, feeding patterns of individual adult cattle are widely variable (DeVries et al., 2003a; Melin et al., 2005), indicating that unknown mechanisms control individual feeding times and meal pattern preferences. Further, individual animals are relatively consistent in diurnal feeding patterns; withincow variability in feeding patterns has been found to be small compared with between-cow variability (Vasilatos and Wangsness, 1980; Melin et al., 2005). This suggests that individual cows may develop characteristic feeding patterns (Melin et al., 2005).

Little is known about factors that may influence the development of characteristic feeding patterns and the time frame in which these patterns may develop. However, there is evidence that environmental factors early in life may affect development of feeding behavior, especially when experiences occur during the critical period of transition from nonruminant to ruminant (Arnold and Maller, 1977; Provenza and Balph, 1987; Squibb et al., 1990). Whereas much research to date has focused on the potential for early environment to shape the development of feed preferences (e.g., plant 
species: Arnold and Maller, 1977; feed flavors: Simitzis et al., 2008), some evidence suggests that early experiences can influence meal patterns. For example, dairy calves offered grass during the milk feeding stage have been found to eat for longer periods when turned out to pasture after weaning (Phillips, 2004). To some degree, feeding patterns are controlled by satiety factors, such as physical fill and metabolic signals (Forbes, 2007), that are similar between animals. For example, milk meal size in calves is positively correlated with latency to the next meal (Senn et al., 2000), suggesting that satiety related to amount of feed ingested influences the distribution of meals. Meal initiation, however, may depend on cognitive factors, such as learned cues. There is evidence that response to external cues associated with feeding is not affected by satiety state (Weingarten, 1983). Thus, the development of individual feeding patterns may depend on prior experiences and learning.

Feeding patterns of dairy calves during the milk feeding stage are highly subject to milk feeding level, which ranges considerably on farm. With ad libitum provision of milk, calves exhibit circadian feeding patterns, characterized by frequent small meals during daylight and increased activity at sunrise and sunset (Senn et al., 2000). It is, however, common practice to provide milk at a restricted rate of approximately $10 \%$ of a calf's birth weight (approximately 4 to $5 \mathrm{~L} / \mathrm{d}$ ), which is less than $50 \%$ of ad libitum intake (Appleby et al., 2001; Khan et al., 2011) and, therefore, constrains milk meal patterns (Appleby et al., 2001; De Paula Vieira et al., 2008). Restricted milk feeding also results in greater solid feed consumption before weaning (Appleby et al., 2001; Jasper and Weary, 2002).

It is clear that milk feeding level has great potential to influence the development of feeding behavior during the milk feeding stage. No studies to date have, however, investigated whether this early influence on development of feeding patterns may result in long-term differences in postweaning feeding patterns. If there are postweaning effects of early milk feeding method on feeding patterns, determining the longevity of these effects would provide insight into whether feeding patterns established during the milk feeding stage are ultimately overridden by other factors, or whether early experiences are a long-term source of the variation in feeding behavior seen in adult cattle.

The objectives of this study were to evaluate how milk feeding level [restricted at $5 \mathrm{~L} / \mathrm{d}$ (RES) or ad libitum (ADL)] influences development of feeding behavior throughout the milk feeding stage, and to assess whether differences in preweaning feeding patterns persist following weaning. It was hypothesized that feeding patterns of weaned calves would be affected by milk allowance during the milk feeding stage and that characteristics of these feeding patterns would be maintained in the postweaning stage.

\section{MATERIALS AND METHODS}

\section{Animals and Housing}

Twenty male Holstein calves were used in this study. Calves received colostrum and were enrolled in the study within $24 \mathrm{~h}$ of birth. On the day they were placed on the study, all calves received injections of $2 \mathrm{~mL}$ of a vitamin supplement containing vitamins $\mathrm{A}, \mathrm{D}$, and E (E-Master; Vétoquinol Canada Inc., Lavaltrie, QC, Canada), $1 \mathrm{~mL}$ of selenium (Dystosel; Pfizer Animal Health, Kirkland, QC, Canada), and $1 \mathrm{~mL}$ of tulathromycin (Draxxin; Pfizer Animal Health) as a preventive measure to reduce incidence of illness (Stanton et al., in press). Calves were housed within individual pens (1.2 $\times 1.8 \mathrm{~m}$; width $\times$ depth) at the University of Guelph Kemptville Campus Dairy Education and Research Centre (Kemptville, ON, Canada) and were managed according to the standard operating procedures of this research station and the guidelines set by the Canadian Council on Animal Care (CCAC, 2009). The interior of each pen was bedded with wood shavings. Bedding was replaced weekly and fresh bedding was added as needed. The front of each pen had 2 openings for access to pails $($ diameter $=25.4 \mathrm{~cm}$, height $=23.0 \mathrm{~cm}$, capacity $=8 \mathrm{~L})$ mounted on the outside. Water was provided ad libitum in one pail, and solid feed was provided in the second pail. Pens were located under a 3-sided, roofed shelter to protect from excessive exposure to the elements.

\section{Milk Feeding Procedure}

During the milk feeding stage, all calves were fed acidified milk replacer by an artificial teat (Peach Teats; Skellerup Industries Ltd., Woolston, New Zealand) measuring $32 \mathrm{~mm}$ in diameter and $85 \mathrm{~mm}$ in length, with two 22-mm slits in the end. The feeding setup involved the teat mounted at the front of the pen, attached to a tube fitted with a one-way valve running into buckets placed outside the pen. All buckets, lines, and teats were cleaned daily. Calves were fed $22 \% \mathrm{CP}$ and $18 \%$ fat Shur-Gain High Performance Milk Replacer (Nutreco Canada Inc., Guelph, ON, Canada; Table 1 ), mixed as indicated at a rate of $150 \mathrm{~g} / \mathrm{L}$ of water. Milk replacer was mixed daily in sufficient volume to feed all calves. At the time of preparation, a prediluted form of formic acid [The Acidified Milk Solution (9.8\% formic acid); NOD Apiary Products Ltd., Frankford, ON, Canada] was added to acidify the milk replacer to a target $\mathrm{pH}$ between 4.0 and 4.5 to prevent microbial growth over the course of the day. 
Table 1. Chemical composition of feeds (mean \pm SD; DM basis)

\begin{tabular}{|c|c|c|c|}
\hline Chemical composition $^{1}$ & Milk replacer $^{2}$ & Concentrate $^{3}$ & Pelleted $\operatorname{diet}^{4}$ \\
\hline $\mathrm{DM}(\%)$ & $95.40 \pm 0.30$ & $95.78 \pm 0.39$ & $96.18 \pm 0.14$ \\
\hline $\mathrm{CP}(\%$ of $\mathrm{DM})$ & $21.60 \pm 0.0$ & $19.18 \pm 0.69$ & $22.96 \pm 0.95$ \\
\hline $\mathrm{ADF}(\%$ of $\mathrm{DM})$ & $1.63 \pm 0.06$ & $7.05 \pm 1.17$ & $17.67 \pm 0.45$ \\
\hline $\mathrm{NDF}^{4}(\%$ of DM) & $2.17 \pm 0.32$ & $17.31 \pm 1.26$ & $34.60 \pm 1.22$ \\
\hline NFC ( $\%$ of DM) & $48.93 \pm 0.71$ & $52.70 \pm 2.56$ & $30.87 \pm 0.67$ \\
\hline ME (Mcal/kg of DM) & $3.93 \pm 0.026$ & $2.80 \pm 0.023$ & $2.54 \pm 0.034$ \\
\hline Fat $(\%$ of $D M)$ & $19.77 \pm 0.57$ & $3.93 \pm 0.77$ & $3.44 \pm 0.32$ \\
\hline
\end{tabular}

${ }^{1}$ Values were obtained from chemical analysis of feed samples. NFC $=100-(\% \mathrm{CP}+\% \mathrm{NDF}+\%$ fat $+\%$ ash $)$. $\mathrm{ME}=$ total digestible nutrients $(\mathrm{TDN}) \times 0.04409 \times 0.82$ [calculated according to NRC (2001) equations].

${ }^{2}$ Shur-Gain High-Performance Milk Replacer (Nutreco Canada Inc., Guelph, ON, Canada).

${ }^{3}$ Supplied by Rooney's Feeds (Iroquois, ON, Canada), containing (on an as-is basis) $36.5 \%$ corn, $28 \%$ calf starter supplement supplied by Shur-Gain (Nutreco Canada Inc.), 20\% rolled barley, $10 \%$ rolled oats, $2.5 \%$ dilute monensin sodium, $2 \%$ molasses, and $1 \%$ soybean oil.

${ }^{4}$ Shur-Gain High Fiber 20\% Dairy Heifer Ration (Nutreco Canada Inc.).

\section{Experimental Design and Diets}

Upon enrollment, calves were assigned to 1 of 2 milk feeding levels: (1) ADL and (2) RES (5 L/d, containing $750 \mathrm{~g}$ of milk replacer/d). Birth weights were similar for both calves fed ADL and RES $(44.3 \pm 4.1 \mathrm{~kg}$ and $43.7 \pm 5.1 \mathrm{~kg}$, respectively; $P=0.76$ ). The RES level of milk restriction was chosen to approximate conventional on-farm milk feeding level. A recent Canadian survey indicated that the median milk allotment for dairy calves is between 4 and $5 \mathrm{~L} / \mathrm{d}$, depending on the age of the calf (Vasseur et al., 2010). Treatments were assigned alternately, such that calves assigned to opposite treatments were adjacent to one another. For calves fed ADL, fresh milk replacer was delivered at $0800 \mathrm{~h}$, in the amount required to ensure unrestricted intake. Calves on the RES treatment received their milk replacer allotment in 2 daily feedings of $2.5 \mathrm{~L}$ at 0800 and $1600 \mathrm{~h}$. Calves received milk for the first 7 wk of life. Both treatment groups were weaned during wk 7 by gradually reducing milk intake by $25 \%$ three times. For RES calves, daily milk allotments during each respective day in wk 7 were (in L/d) $5,3.75,3.75$, $2.5,2.5,1.25$, and 1.25 , split between 2 daily feedings. For ADL calves, the average individual intake across wk 6 was similarly reduced incrementally by $25 \%$ per day. During the milk feeding stage, all calves had ad libitum access to a textured concentrate (Table 1).

On the first day of wk 8, a complete pelleted diet (Shur-Gain High Fiber 20\% Heifer Ration; Nutreco Canada Inc.; Table 1) was offered ad libitum in place of concentrate. Fresh feed was delivered daily at 0900 $\mathrm{h}$ and orts were weighed and discarded daily. Calves remained on the study, receiving the pelleted diet, for an additional 7 wk. A single solid feed type was provided throughout the study to eliminate any poten- tially confounding effects of intake of multiple, differing components on the assessment of feeding patterns.

\section{Intake and Growth Measurements}

Intake of solid feed (and milk during the milk feeding stage) was recorded daily based on weights of offered and refused feed. Calves were weighed at the same time each day on 2 consecutive days each week. Repeated measurements were made to obtain an accurate weekly weight and to account for day-to-day variability.

\section{Feed Sampling and Analysis}

For determination of DM and nutrient content of the feed and assessment of daily DMI and nutrient intakes of the calves, fresh feed was sampled weekly and individual orts from each calf were sampled twice weekly (on d 1 and 4), just before removal and delivery of fresh feed. This sampling protocol was consistent throughout the study; however, samples taken changed from the concentrate offered during the milk feeding stage, to the complete pelleted diet in the postweaning stage. All samples were immediately frozen at $-20^{\circ} \mathrm{C}$ until they were further analyzed.

Samples taken for DM and chemical analysis were thawed and oven dried at $55^{\circ} \mathrm{C}$ for $48 \mathrm{~h}$ and then ground to pass through a 1-mm screen (Wiley mill; Arthur H. Thomas Co., Philadelphia, PA). These samples were pooled by calf and time interval (milk feeding or postweaning) and sent to Cumberland Valley Analytical Services Inc. (Maugansville, MD) for analysis of DM $\left(135^{\circ} \mathrm{C}\right.$; AOAC International, 2000 ; method 930.15), ash $\left(535^{\circ} \mathrm{C}\right.$; AOAC International, 2000 ; method 942.05), ADF (AOAC International, 2000; method 973.18), NDF with heat-stable $\alpha$-amylase and sodium 
sulfite (Van Soest et al., 1991), and $\mathrm{CP}(\mathrm{N} \times 6.25$; AOAC International, 2000: method 990.03; Leco FP528 nitrogen analyzer; Leco Corp., St. Joseph, MI).

\section{Behavioral Data Collection and Meal Analysis}

The behavior of all calves was recorded continuously throughout the study using 8 color video cameras (day/ night camera, model no. WV-CP504; Panasonic, Osaka, Japan) fitted with an F0.95/2.8- to 8-mm lens (Fujinon CCTV lens; Fuji, Tokyo, Japan). Cameras were connected to a digital video recorder (digital disk recorder, model no. WJ-HD616K; Panasonic) set to record at 15 images/s. Cameras were positioned above the pens such that each individual pen was fully visible from one of the cameras (placed approximately $2 \mathrm{~m}$ in front of the pens and $4 \mathrm{~m}$ from the pen floor). Four red lights (100 W) were spaced evenly between cameras and placed on a timer to provide enough light to record during nighttime hours.

Calves were observed individually for the first $5 \mathrm{~d}$ of wk 3 and 6 (during the milk feeding stage) and wk 8,11 , and 14 (postweaning). In the milk feeding stage, instantaneous scans were performed at intervals of $30 \mathrm{~s}$ (as validated previously by Miller-Cushon and DeVries, 2011) for milk feeding (nutritive sucking; defined as taking place when a calf's mouth was closed on the teat and milk was visible in the tube running to the milk bucket), nonnutritive sucking (for RES calves only, defined as taking place when a calf's mouth was closed on the teat after milk was finished), and solid feed intake (defined as taking place when a calf's head was lowered in the feed bucket). In the postweaning stage, instantaneous scans were performed at intervals of $30 \mathrm{~s}$ for solid feed intake. Data obtained from instantaneous recording was used to approximate behavior throughout the day by assigning a $30 \mathrm{~s}$ block of time to each positive scan, as validated and described by Miller-Cushon and DeVries (2011).

Meal analysis was performed on the $5 \mathrm{~d}$ of data collected for individual calves in each observation week. For weeks during the milk feeding stage (wk 3 and 6), meal analysis was performed on both milk and solid feed meals. For RES calves, this analysis was performed on both milk feeding (sucking on the teat while milk was available) and total sucking (milk feeding and sucking on the teat once milk was finished). Meal (or sucking bout) criteria were determined for individual calves in each week using a software package (MIX 3.1.3; MacDonald and Green, 1988) that fitted a mixture of normal distributions to the distributions of $\log _{10}$-transformed time intervals between the recorded periods of time spent feeding or sucking. A bimodal normal distribution was fitted to the distribution of intervals for each calf in each week. As described by (DeVries et al., 2003b), the meal criterion was determined from these modeled distributions as the time point at which the distribution curve of intermeal intervals intersected the distribution curve of intrameal intervals. It was not possible to calculate RES milk meal criteria due to few within-meal pauses; thus, RES milk meal start and end points were defined for each calf by the time of milk delivery and time the milk was finished. Across all calves, solid feed meal criteria averaged $16.3 \pm 7.9$ (mean \pm SD) min in the milk feeding stage and $15.6 \pm 3.9 \mathrm{~min}$ in postweaning stage. Milk meal criteria for ADL calves averaged $14.3 \pm 4.2 \mathrm{~min}$. Total sucking bout criteria (milk feeding and nonnutritive sucking) for RES calves averaged $19.4 \pm 6.2 \mathrm{~min}$.

Meal criteria were used to calculate daily meal frequency and total daily meal time for each calf in each recorded week. Daily meal frequency was determined by counting the number of intervals between visits to the feed pail (or teat) that exceeded the meal criterion. Total daily meal time was calculated as the sum of all recorded feeding time (total daily feeding time) and all nonfeeding time periods shorter than the meal criterion. Data from meal analysis (total daily feeding time, daily meal frequency, and total daily meal time) were used, in combination with values for daily intake corresponding to observation days, to generate several additional variables related to feeding behavior. These included meal duration (meal time/meal frequency), meal size (daily intake/meal frequency), rate of intake (intake/ feeding time), and feeding time per meal (feeding time/ meal frequency). A similar analysis was performed for RES total sucking (milk feeding and nonnutritive sucking), using the sucking bout criteria. Data from this sucking bout analysis were compared with ADL milk feeding behavior to compare total sucking behavior between treatments.

\section{Statistical Analyses}

One calf (on RES treatment) was removed from the trial during wk 12 for health reasons unrelated to the trial; thus, data from only 9 RES calves was analyzed for wk 12, 13, and 14 of the study. All data were summarized and analyzed separately by stage of life (milk feeding stage and postweaning). Data for DMI, nutrient intakes, BW, and ADG were summarized for each calf for each week on treatment. Daily values for meal characteristics were averaged by calf across the $5 \mathrm{~d}$ in each week in which behavioral observations were made. To examine the effect of treatment, data were analyzed using PROC MIXED of SAS (SAS Institute Inc., Cary, 
$\mathrm{NC}$ ), treating week as a repeated measure. The model included the fixed effects of week, treatment, and week by treatment interaction, and the random effect of calf within treatment. The Toeplitz model was selected as the variance-covariance matrix structure for intake and weight data on the basis of best fit according to Schwarz's Bayesian information criterion. The autoregressive model was selected as the variance-covariance matrix structure for meal data on the basis of best fit according to Schwarz's Bayesian information criterion.

An analysis of diurnal patterns of feeding behavior was performed on feeding and meal time in wk 6,8 , and 14, and milk feeding time, milk meal time, total sucking time, and total sucking bout time in wk 3 and 6 . For this analysis, hourly totals of time spent performing each behavior were averaged by calf across the $5 \mathrm{~d}$ of observation in each week. Data were analyzed separately in each week using the MIXED procedure of SAS (SAS Institute Inc.), treating hour as a repeated measure. The model included the fixed effects of hour, treatment, and hour by treatment interaction, and the random effect of calf within treatment. The autoregressive model was selected as the variance-covariance matrix structure for diurnal pattern data on the basis of best fit according to Schwarz's Bayesian information criterion.

Prior to summarizing individual calves' meal data by week, it was noted that considerable within-calf day-today variability in daily values existed for meal characteristics during the postweaning stage. Therefore, a post hoc analysis was also performed on individual variability in feeding behavior to assess the effects of treatment and week on individual day-to-day variability. For this analysis, the coefficient of variation (Friggens et al., 1998) was calculated for each calf in each week in which behavioral observations were made, as the standard deviation of the daily values for meal characteristics divided by the mean value for meal characteristics in that week. Variability data were analyzed similarly to meal data, using PROC MIXED of SAS (SAS Institute Inc.) to assess the effects of treatment, treating week as a repeated measure. The autoregressive model was selected as the variance-covariance matrix structure for this data on the basis of best fit according to Schwarz's Bayesian information criterion.

For all analyses, preliminary screening of the data revealed that dependent variables were normally distributed. Assumptions of homogeneity of variance were verified by plotting residuals from the model against predicted values. All values reported are least squares means. Significance was declared at $P \leq 0.05$, and trends reported at $0.05<P \leq 0.10$.

\section{RESULTS}

\section{Feed Intake and Performance}

Milk replacer intake of ADL calves increased over time, compared with the fixed rate offered to RES calves (Table 2). On average, in the milk feeding stage, ADL calves consumed more than twice the amount of milk replacer offered to RES calves. Prior to weaning, solid feed intake was affected by milk feeding level (Table 2). Solid feed intake during the milk feeding stage is shown over time in Figure 1a (wk 1 to 7 ). Calves fed RES consistently consumed more concentrate than ADL and increased their intake over time to a greater extent. Due to their increasing consumption of milk replacer, total DMI of ADL calves increased more over time and was greater overall (Table 2). Intakes of CP, NFC, and ME were correspondingly subject to treatment by week interactions $(P<0.001)$ and ADL calves also had greater $(P<0.001)$ overall intakes of $\mathrm{CP}(0.41$ vs. $0.23 \mathrm{~kg} / \mathrm{d}, \mathrm{SE}=0.017), \mathrm{NFC}(0.92$ vs. $0.56 \mathrm{~kg} / \mathrm{d}$, $\mathrm{SE}=0.042)$, and $\mathrm{ME}(7.23$ vs. $3.87 \mathrm{kcal} / \mathrm{d}, \mathrm{SE}=0.30)$ than did RES calves. In contrast, NDF intake increased more over time for RES calves, consistent with their greater intake of concentrate which is higher in NDF than milk replacer (Table 1). Overall, RES calves consumed more NDF than ADL before weaning (0.098 vs. $0.061 \mathrm{~kg} / \mathrm{d}, \mathrm{SE}=0.009, P=0.012)$. Calf $\mathrm{BW}$ was subject to a treatment by week interaction during the milk feeding stage, with ADL calves having greater ADG (Table 2). Calf growth over time is shown in Figure $1 \mathrm{~b}$ (wk 1 to 7). During the week of weaning, ADG of ADL calves plateaued, whereas RES calves maintained more consistent growth $(-0.03$ vs. $0.7 \mathrm{~kg} / \mathrm{d}, P<0.001)$.

During the postweaning stage, orts were similar for both ADL and RES treatment groups (11.7\% vs. $12.8 \%$, $\mathrm{SE}=1.5, P=0.5)$. Intake of the complete pelleted diet was subject to a treatment by week interaction (Table 2 ), depicted in Figure 1a (wk 8 to 13). Immediately postweaning, DMI was greater for RES calves than ADL, but DMI of ADL calves increased over time to a greater extent. Corresponding to DMI, nutrient intakes were subject to treatment by week interactions $(P<$ $0.01)$ but not overall treatment effects $(P>0.21)$. On average, calves consumed $0.76 \mathrm{~kg}$ of $\mathrm{CP} / \mathrm{d}, 1.12 \mathrm{~kg}$ of $\mathrm{NDF} / \mathrm{d}, 1.0 \mathrm{~kg}$ of NFC/d, and $8.32 \mathrm{kcal}$ of $\mathrm{ME} / \mathrm{d}$ during the postweaning stage. As illustrated in Figure 1b (wk 8 to 13 ), ADG was similar between treatments in the postweaning stage. Thus, greater BW of ADL calves were maintained (Table 2). Because postweaning DMI was similar over time, RES calves had greater DMI as a percentage of $\mathrm{BW}$ in the postweaning stage (Table 2). 
Table 2. Intakes and weight gain of calves raised on different milk feeding levels during the milk feeding stage and postweaning ${ }^{1,2}$

\begin{tabular}{|c|c|c|c|c|c|c|}
\hline \multirow[b]{2}{*}{ Item } & \multicolumn{2}{|c|}{ Treatment (Trt) } & \multirow[b]{2}{*}{$\mathrm{SE}$} & \multicolumn{3}{|c|}{$P$-value } \\
\hline & $\mathrm{ADL}$ & RES & & $\mathrm{Wk}^{3}$ & Trt & Trt $\times W k$ \\
\hline \multicolumn{7}{|l|}{ Milk feeding stage } \\
\hline Milk replacer DMI (kg/d) & 1.77 & 0.666 & 0.072 & $<0.001$ & $<0.001$ & $<0.001$ \\
\hline Solid feed DMI $(\mathrm{kg} / \mathrm{d})$ & 0.098 & 0.452 & 0.057 & $<0.001$ & $<0.001$ & $<0.001$ \\
\hline Total DMI $(\mathrm{kg} / \mathrm{d})$ & 1.87 & 1.12 & 0.083 & $<0.001$ & $<0.001$ & $<0.001$ \\
\hline $\mathrm{ADG}^{4}(\mathrm{~kg} / \mathrm{d})$ & 1.2 & 0.6 & 0.07 & $<0.01$ & $<0.01$ & 0.58 \\
\hline $\mathrm{BW}^{4}(\mathrm{~kg})$ & 63.2 & 50.8 & 2.5 & $<0.001$ & 0.004 & 0.01 \\
\hline \multicolumn{7}{|l|}{ Postweaning stage } \\
\hline DMI $(\mathrm{kg} / \mathrm{d})$ & 3.38 & 3.17 & 0.11 & $<0.001$ & 0.29 & 0.013 \\
\hline DMI ( $\%$ of BW) & 2.71 & 3.16 & 0.15 & $<0.001$ & 0.006 & 0.13 \\
\hline BW (kg) & 121.9 & 100.9 & 3.5 & $<0.001$ & $<0.001$ & 0.58 \\
\hline $\operatorname{ADG}(\mathrm{kg} / \mathrm{d})$ & 1.2 & 1.2 & 0.05 & $<0.001$ & 0.89 & 0.13 \\
\hline \multicolumn{7}{|c|}{$\begin{array}{l}{ }^{1} \text { Data averaged by week for calves fed ad libitum }(\mathrm{ADL} ; \mathrm{n}=10) \text { before weaning and calves re- } \\
\text { stricted at } 5 \mathrm{~L} / \mathrm{d} \text { (RES; } \mathrm{n}=10 \text { from wk } 1 \text { to } 11, \mathrm{n}=9 \text { from wk } 12 \text { to } 14 \text { ) before weaning. } \\
{ }^{2} \text { Milk feeding stage }=\text { wk } 1 \text { to } 7 \text {; postweaning stage }=\text { wk } 8 \text { to } 14 .\end{array}$} \\
\hline
\end{tabular}

\section{Feeding Behavior}

Milk feeding level affected the milk feeding patterns of calves. Daily milk meal characteristics for wk 3 and 6 are reported in Table 3. Calves fed ADL had greater milk meal frequency ( $>7$ meals/d vs. 2 meals/d for RES calves) and had meals that were approximately 1.5 times the duration of RES milk meals. The time spent sucking per meal and the rate of intake were similar between treatments. Meal size increased over time for ADL calves but was held constant due to feeding management for RES calves. Certain aspects of milk feeding behavior developed over time across treatments; the rate of intake increased between wk 3 and 6 and, correspondingly, meal duration tended to decrease. Meal frequency and sucking time per meal remained similar between wk 3 and 6 .

The diurnal patterns of milk feeding time and meal time were subject to a significant $(P<0.001)$ treatment by hour interaction in wk 3 and 6 . Diurnal patterns of milk feeding time and meal time in wk 6 are depicted in Figure 2a. Restricted-fed calves consumed their milk allotment immediately at the time of delivery in a single short meal without pausing. Thus, milk feeding time was equivalent to meal time for RES calves. RES calves had 2 peaks in feeding time at fresh milk delivery (0800 and $1600 \mathrm{~h}$ ) and no other feeding activity throughout the rest of the day. In contrast, ADL calves spent much more time feeding over the course of the day and had meals consisting of frequent pauses. The largest peak in feeding activity for ADL calves occurred at the time of fresh milk delivery $(0800 \mathrm{~h})$, with an increase in activity beginning around sunrise. Lesser peaks for ADL calves corresponded to afternoon milk delivery for RES calves (1600 h) and sunset (approximately $2045 \mathrm{~h}$ in wk 6).

Restricted calves spent considerable time sucking on the teat once milk was finished and at times of day when milk was not provided. Daily total sucking bout characteristics, including nonnutritive sucking for RES calves in addition to milk feeding for both treatments, are described for wk 3 and 6 in Table 3. Sucking bout frequency was subject to a treatment by week interaction, with RES calves having more frequent sucking bouts than ADL in wk 3, and less frequent bouts in wk 6. Although RES calves had consistently longer sucking bouts than ADL, sucking time per bout was similar between treatments, indicating that RES calves spent more time pausing during bouts of nonnutritive sucking.

Diurnal patterns of total sucking bout time (milk feeding and nonnutritive sucking, as well as pauses within bouts) and total sucking time (milk feeding and nonnutritive sucking time) were subject to a significant $(P<0.001)$ treatment by hour interaction in wk 3 and 6 . The diurnal patterns of sucking bout time and sucking time are depicted for wk 6 in Figure 2b. Restricted calves spent more time sucking than ADL calves at 2 peak times falling between sunrise (approximately 0515 $\mathrm{h}$ in wk 6) and $2 \mathrm{~h}$ after their morning feeding, and for $2 \mathrm{~h}$ surrounding afternoon feeding. Calves fed ADL spent more time sucking than RES calves during offpeak times, although RES calves had a similar peak in sucking time just before sunset (approximately $2045 \mathrm{~h}$ in wk 6).

Solid feed intake behavior during the milk feeding stage is reported in Table 3. Meals of RES calves in- 

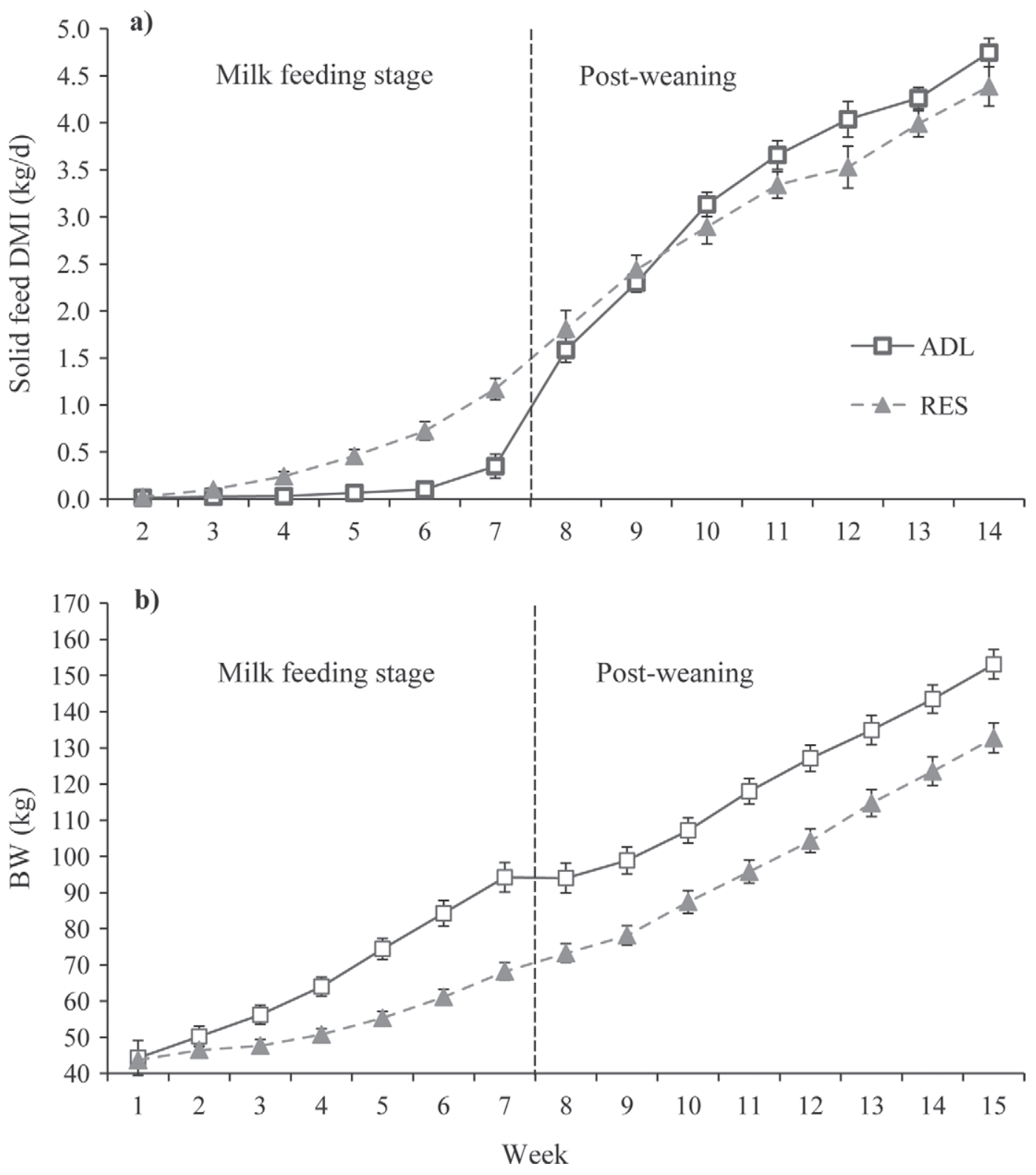

Figure 1. Dry matter intake (a) and BW (b) of calves throughout weeks of the study. Values are averaged over each week for 10 calves/ treatment [excluding 1 calf restricted at $5 \mathrm{~L} / \mathrm{d}$ (RES) in wk 12 to 14]. ADL = calves fed milk ad libitum before weaning; RES = calves fed milk at a restricted rate of $5 \mathrm{~L} / \mathrm{d}$ before weaning.

creased in size over time to a greater extent than meals of ADL calves. Restricted calves also had more frequent meals, longer meals, and spent more time feeding per meal than ADL calves. The rate of intake was similar between treatments. Feeding patterns developed over time; between wk 3 and 6 , daily meal frequency and rate of intake increased, whereas meal duration tended to increase. Diurnal patterns of feeding time and meal time for solid feed in wk 6 (Figure 2) were subject to a significant $(P<0.001)$ hour by treatment interaction. Restricted calves had peaks in feeding activity at 0700 $\mathrm{h}$ (the time at which the milk feeding apparatus was removed for cleaning), feed delivery (0900 h), afternoon milk feeding $(1600 \mathrm{~h})$, and sunset $(2045 \mathrm{~h}$ in wk 6). The ADL calves had much smaller peaks in feeding activity that corresponded roughly to RES peaks in feeding activity.

Solid feed meal characteristics in the postweaning period are reported in Table 4. Meal frequency, meal duration, and feeding time per meal were similar between treatments after weaning. Meal size and rate of intake were subject to a treatment by week interac- 
Table 3. Effect of milk feeding level on milk feeding, total sucking behavior, and solid feeding behavior ${ }^{1,2}$

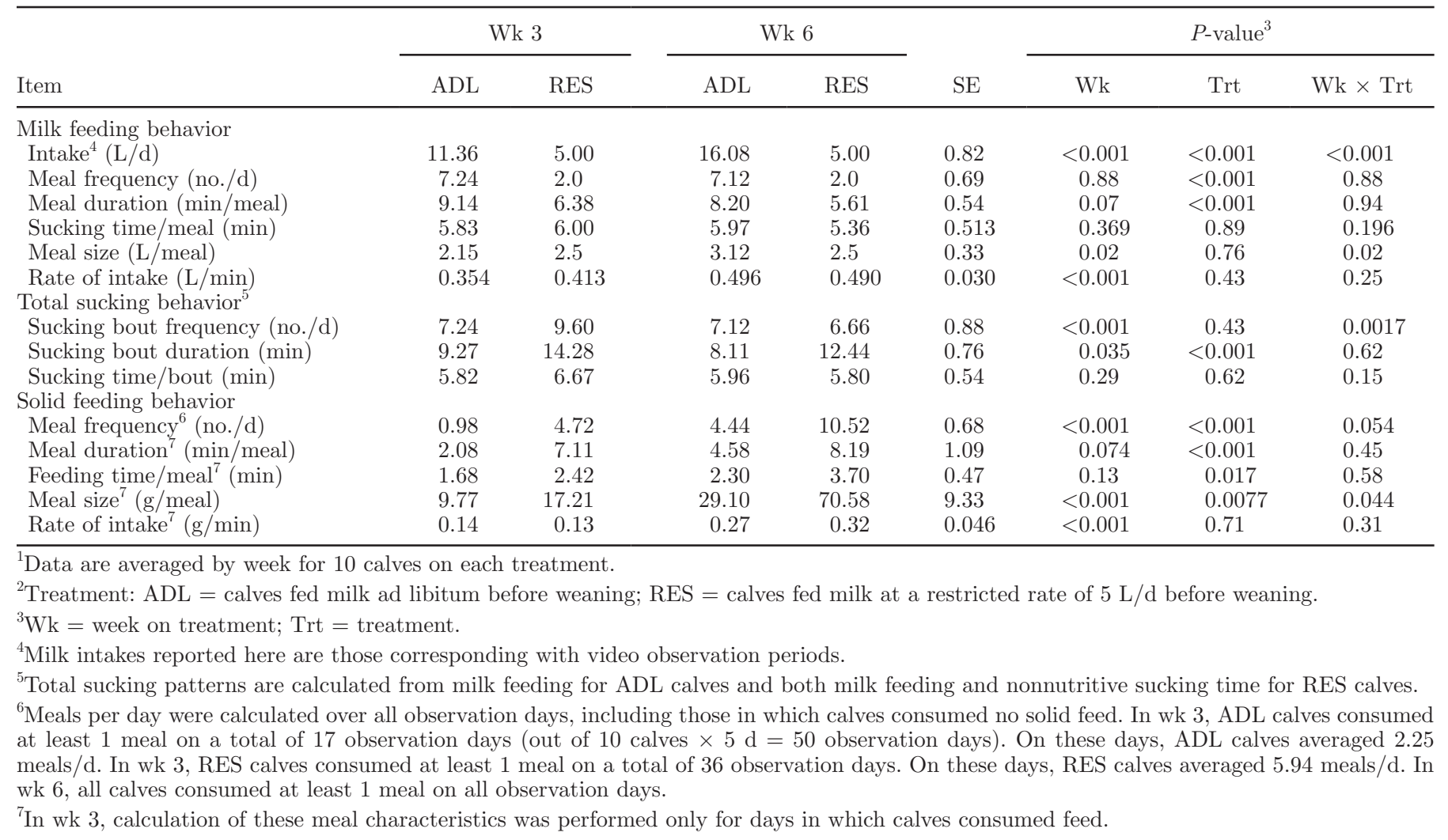

tion. The ADL calves had a lower rate of intake and consumed smaller meals than RES calves initially after weaning, and increased their rate of intake and meal size more substantially over time. Meal frequency increased over time, whereas meal duration and feeding time per meal decreased. Diurnal patterns of meal time and feeding time initially after weaning (wk 8) and 7 wk after weaning (wk 14) are shown in Figures 3a and $4 \mathrm{~b}$, respectively. Meal time was subject to a treatment by hour interaction initially after weaning (wk $8 ; P=$ 0.028). Calves raised on ADL milk had similar patterns of meal time to RES calves throughout most of the day in wk 8 , but had a higher peak in meal time at time of feed delivery $(0900 \mathrm{~h})$. In the analysis of diurnal feeding time in wk 8 , a tendency $(P=0.089)$ for a treatment by hour interaction was also detected. This interaction reflects slight differences in time spent feeding at peak feeding times; calves raised on ADL milk had a larger peak in feeding time at sunrise (approximately $0530 \mathrm{~h}$ in wk 8), and lower peaks in feeding time in late afternoon. At time of feed delivery, both treatments had a similar peak in feeding time, whereas ADL calves had a greater peak in meal time; this suggests that ADL calves paused more during the first meal after feed delivery than RES calves. In wk 14, neither meal time nor feeding time were subject to a treatment by hour interaction. The largest peak in feeding time occurred at feed delivery $(0900 \mathrm{~h})$, with an increase in activity beginning around sunrise (at approximately $0620 \mathrm{~h}$ in wk 14), and the second largest peak occurred at sunset (at approximately $1945 \mathrm{~h}$ in wk 14).

The analysis of individual variability of daily meal characteristics revealed that ADL calves were more consistent day to day in their postweaning feeding behavior (Table 4). Variability in DMI, meal size, and rate of intake was subject to a treatment by week interaction and treatment effect, with RES calves having a more substantial decrease in day-to-day variability between weeks but greater overall variability. The ADL calves also had less individual day-to-day variability in feeding time per meal. Individual day-to-day variability of meal characteristics was subject to a week effect, with variability decreasing over time across treatments.

\section{DISCUSSION}

It has been widely reported that milk feeding level affects intake and growth of dairy calves (Appleby et al., 2001; Jasper and Weary, 2002; Khan et al., 2011). Milk replacer intake for ADL calves was similar to other values reported in the literature (e.g., average of $14 \mathrm{~L} / \mathrm{d}$ over the first 6 wk of life; Borderas et al., 2009), 

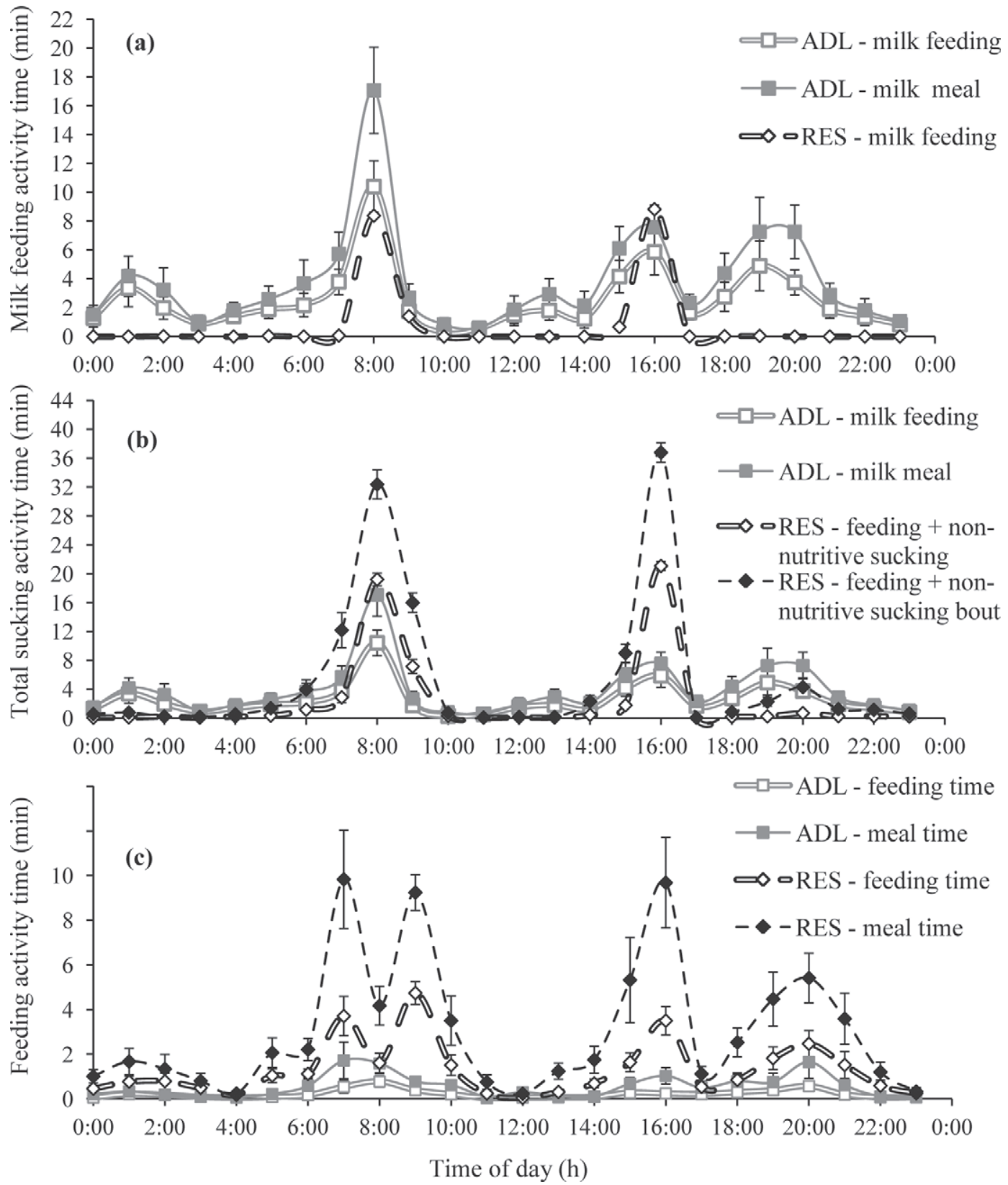

Figure 2. Comparison of diurnal patterns of (a) milk feeding activity, (b) total sucking activity [including nonnutritive for calves restricted at $5 \mathrm{~L} / \mathrm{d}(\mathrm{RES})]$, and (c) solid feed feeding activity of calves provided with ad libitum milk (ADL) and RES treatment in wk 6 of life. Milk feeding and meal time were equivalent for RES calves (due to lack of pauses in meals) and are represented by a single line in (a). Time spent performing each behavior is summarized by hour within treatment (averaged across $5 \mathrm{~d}$ of observation/wk and 10 calves/treatment).

as was the rate of weight gain of ADL calves (0.8 to $1.1 \mathrm{~kg} / \mathrm{d}$ is commonly reported; Appleby et al., 2001; Jasper and Weary, 2002; Hepola et al., 2008). Starter intake was delayed due to greater milk intake, as is also commonly reported (Appleby et al., 2001; Jasper and Weary, 2002).

Milk feeding level influenced postweaning performance, with calves having comparable postweaning intake and $\mathrm{ADG}$, but ADL calves maintaining greater
BW. Although a similar result was reported by Jasper and Weary (2002), this effect of milk feeding level is not consistent across the literature. The potential for greater milk feeding to result in greater postweaning BW appears to depend on sufficient solid feed intake before removal of milk, which can be encouraged through a gradual weaning method (Khan et al., 2007) or social facilitation in group-housed calves (Chua et al., 2002; De Paula Vieira et al., 2010). Calves fed ADL in the 


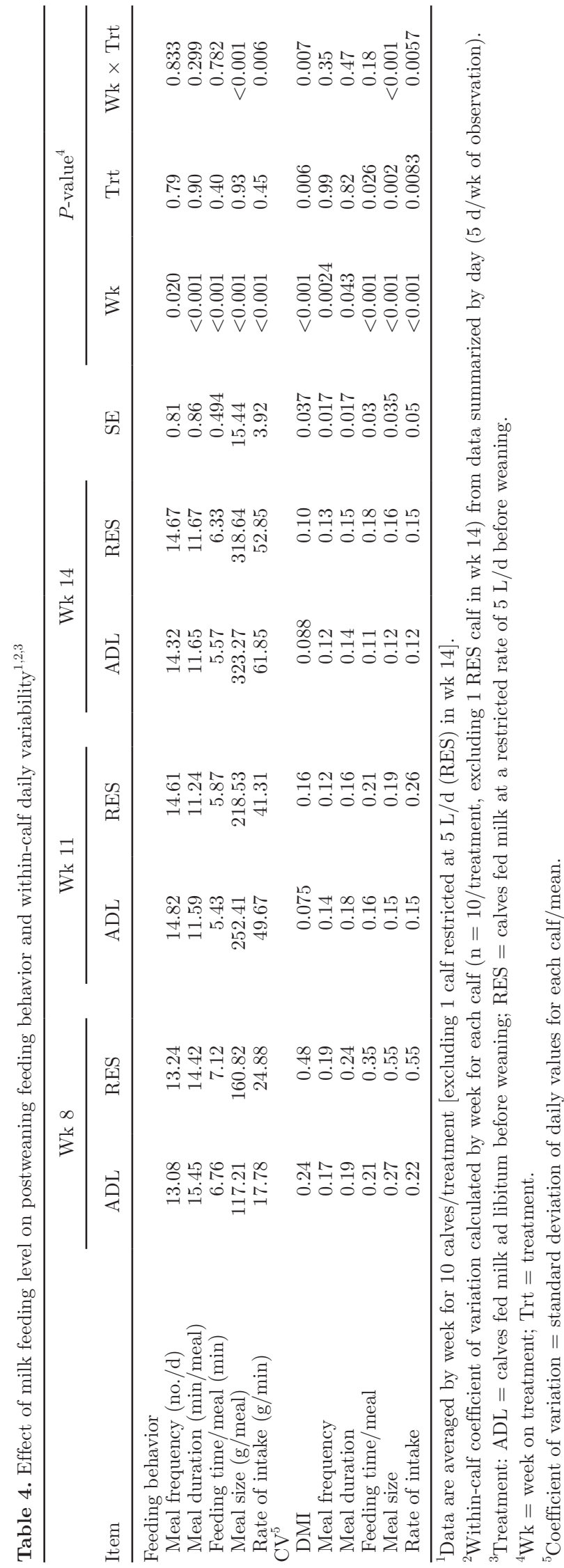

present study plateaued in growth briefly during the week of weaning, suggesting that management during the week of weaning could have been improved. Greater postweaning intake as a percentage of $\mathrm{BW}$ for RES calves, yet similar ADG, suggests that these animals were not utilizing nutrients as efficiently for growth as ADL calves. The reason for this difference is unclear; however, it could be speculated that restricted nutrient supply early in life had a long-term negative effect on metabolism of the calves (as reviewed by Bach, 2012).

Milk feeding behavior was greatly influenced by milk feeding level. In contrast to the single peaks of continuous feeding performed by RES calves, ADL calves had frequent meals interspersed with pauses over the course of the day. Meal frequencies and durations of ADL calves were similar to values reported previously for suckling calves (i.e., 4 to 10 suckling bouts/d, 7 to $10 \mathrm{~min}$ in duration; reviewed by de Passillé, 2001) and calves fed ad libitum from a teat (De Paula Vieira et al., 2008; Borderas et al., 2009). Similar to results reported by Appleby et al. (2001), ADL calves had a peak in feeding activity corresponding to fresh milk delivery (Figure 2a). Sunrise and sunset elicited feeding activity, as has been reported in both suckling calves (Odde et al., 1985) and calves fed milk ad libitum by a computer-controlled milk feeder (Senn et al., 2000). Calves fed ADL also had increased activity at time of afternoon milk delivery for RES calves, possibly elicited by the presence of the experimenters or auditory cues from adjacent RES calves.

Milk meals have been found to increase in size and decrease in frequency over time in calves suckled by their dam (Odde et al., 1985; Vitale et al., 1986; Day et al., 1987) and in group-housed calves fed by an automated milk feeder (Jensen, 2009). Similarly in the present study, ADL milk meals became larger over time due to fewer pauses during meals and greater rate of intake, suggesting that calves were feeding more efficiently. In contrast, however, meal frequency was similar between weeks in the present study. This stability of daily meal frequency may relate to calves being individually housed. In the absence of social factors, such as maternal influence (Reinhardt and Reinhardt, 1981) or peer competition and displacement at the teat (von Keyserlingk et al., 2004; Jensen, 2009), less pressure may exist to reduce meal frequency as calves become physically capable of consuming more milk per meal.

Calves in the RES group spent considerable time performing nonnutritive sucking. Similarly, it has been widely reported that feeding group-housed calves restricted amounts of milk by an automated milk feeder results in frequent unrewarded visits to the feeder, and greater daily occupancy times (Hammon et al., 2002; Jensen and Holm, 2003; De Paula Vieira et al., 2008). 

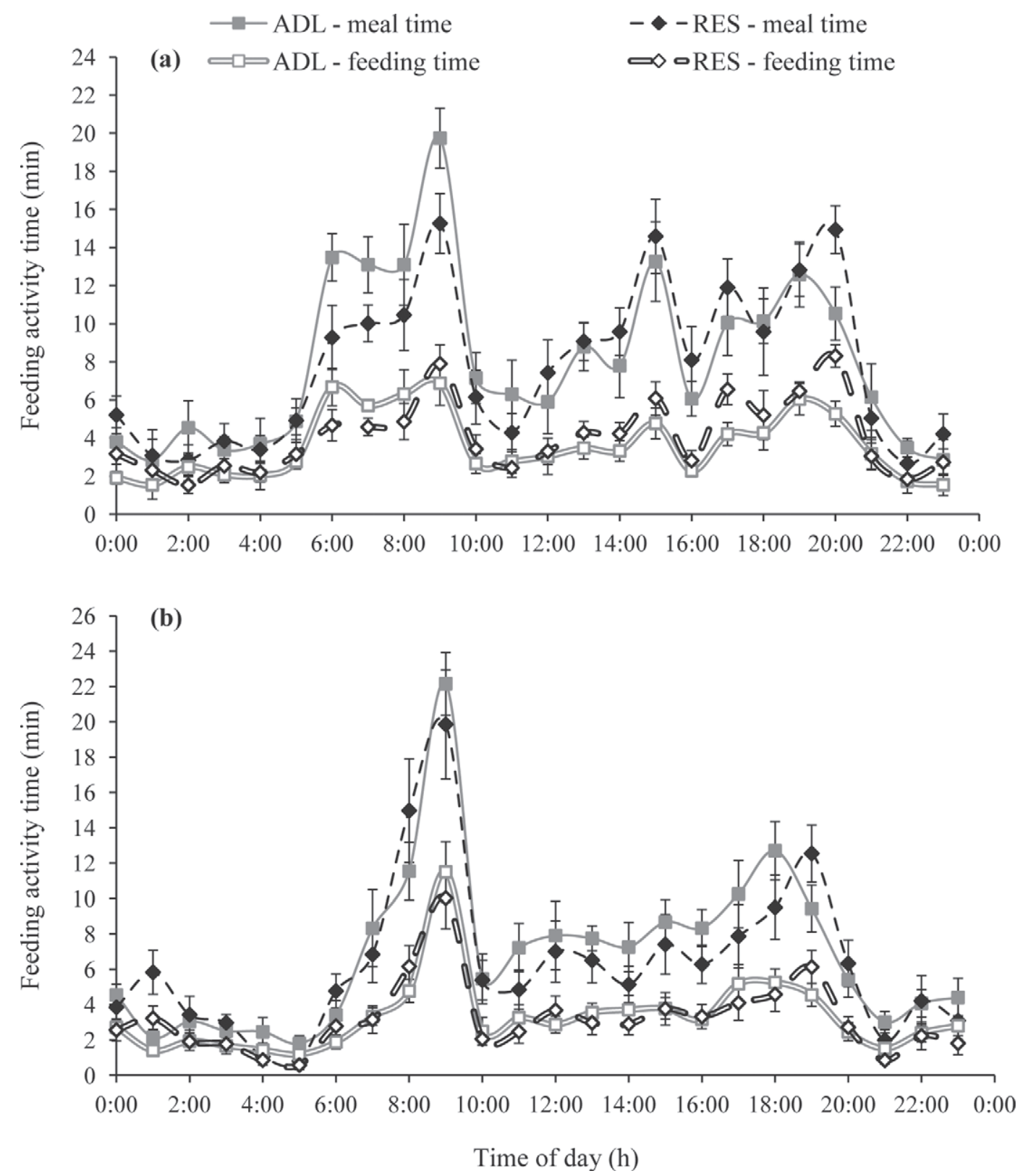

Figure 3. Diurnal patterns of feeding activity of calves raised on ad libitum milk (ADL) or restricted milk (RES) in (a) the first week after weaning (wk 8), and (b) 7 wk after weaning (wk 14). Feeding time and meal time are summarized by hour, with data averaged across 5 d of observation for each calf in each week and 10 calves/treatment (excluding 1 RES calf in wk 14).

Restricted calves had large peaks in nonnutritive sucking time around time of milk delivery (Figure $2 \mathrm{~b}$ ). It is established that the taste of milk elicits sucking in calves (Rushen and de Passillé, 1995), and nonnutritive sucking following a milk meal has been reported previously in calves fed restricted amounts of milk individually (Haley et al., 1998; Herskin et al., 2010) and in groups by an automated feeder (De Paula Vieira et al., 2008). Interestingly, diurnal patterns of total sucking time of RES calves mirrored the feeding pat- terns of ADL calves (Figure 2b), with a small peak in nonnutritive sucking activity seen at sunset, despite the fact that RES calves never had milk available at this time. Nonnutritive sucking or unrewarded visits to a feeder are commonly considered signs of hunger in restricted-fed calves (Jensen and Holm, 2003; De Paula Vieira et al., 2008; Herskin et al., 2010). Thus, RES calves may have been motivated to feed at sunset by the same external light cues as ADL calves, or through social facilitation due to auditory signals while ADL 
calves were feeding and performed nonnutritive sucking in the absence of milk. These results support previous findings suggesting that restricting milk leaves calves hungry, thus compromising their welfare (De Paula Vieira et al., 2008).

Different solid feed meal patterns in the milk feeding stage were not surprising due to the greater quantity of solid feed consumed by RES calves. The effect of milk feeding level on the development of preweaning solid feed meal patterns has not been widely studied. However, feeding behavior of group-housed calves fed concentrate at an automated feeder has been described by Jensen (2006) and Borderas et al. (2009). Similar to the present results, calves fed limited amounts of milk in those studies had more frequent visits than calves fed ad libitum. Meals in the present study were longer and less frequent than visits to the automated feeder described by Jensen (2006) and Borderas et al. (2009), possibly due to individual housing in the present study, which eliminates any effect of competition on meal duration. Total solid feed meal time in the present study is comparable to total concentrate feeder occupancy time by group-housed calves and is similarly greater for calves fed less milk (Jensen, 2006; Borderas et al., 2009).

Contrary to our hypothesis, the differences in feeding behavior in the milk feeding stage did not translate to long-term observable differences in feeding behavior. Thus, milk feeding level does not appear to influence the development of long-term meal patterns. However, short-term differences in behavior were evident immediately after weaning. Initially, calves fed RES had larger meals, driven by greater rate of intake while feeding. Evidence exists that feeding behavior of young ruminants is influenced by early experience with feed. For example, Phillips (2004) found that calves exposed to grass early in life ate for longer when later turned out on pasture, and Arnold and Maller (1977) found that sheep with exposure to a particular plant type had a greater rate of intake while grazing than sheep unfamiliar with the plant. Thus, initial postweaning differences in rate of intake in the present study may have been a result of RES calves having greater experience consuming solid feed before weaning and, consequently, more developed motor skills. Alternatively, rate of intake can be considered an indicator of feeding motivation (Nielsen, 1999); thus, greater rate of intake may have developed in RES calves as a response to hunger during the milk-feeding stage.

Interestingly, milk feeding level also had a short-term effect on diurnal feeding patterns. This effect was most evident at the time of fresh feed delivery (Figure 3a). Although all calves spent a similar amount of time feeding during the peak period in activity corresponding to fresh feed delivery, calves previously fed ADL milk had greater meal time, indicating that they paused more while feeding. A similar difference between treatments can be seen in the peak period in feeding activity at time of fresh milk delivery (Figure 2a), suggesting that this characteristic of milk feeding patterns had a short-term influence on postweaning feeding behavior. The paucity of breaks during RES meals in the milk feeding stage can be attributed to greater feeding motivation due to milk deprivation (De Paula Vieira et al., 2008). Thus, calves that associated feed delivery with alleviation of hunger in the milk feeding stage may have developed a conditioned response of continuous feeding and increased rate of intake at time of feed delivery. In the presence of an unlimited feed source, calves previously fed RES milk eventually responded to fresh feed delivery similarly to ADL calves (Figure 3b). Under commercial conditions, recently weaned calves are often exposed to social factors and varying feed presentations, which could possibly interact with this short-term difference in feeding behavior. For example, in a group-housed environment, calves that are highly motivated to feed at time of feed delivery may be faced with competition if feeding space is limited, possibly affecting DMI. Additionally, weaned heifers may be provided with separate feed components (i.e., concentrates and forages) rather than a uniform feed source, which encourages rapid intake of the concentrate portion in a few large meals (DeVries and von Keyserlingk, 2009). If calves are predisposed to feed continuously upon feed delivery, this method of feed presentation may strengthen this behavioral trait. Further research is needed to investigate the impact of this difference in feeding behavior when calves are managed in different postweaning environments and exposed to different nutritional strategies.

Unexpectedly, RES calves had consistently greater day-to-day variability in postweaning feeding behavior, resulting in greater variability in daily DMI. Several studies suggest that variability in daily DMI is related to health. Increased daily variation in DMI has been found in bull calves with liver abscesses and respiratory disease (Jorgensen et al., 2007) and is considered an indicator of SARA (Owens et al., 1998; Pritchard and Bruns, 2003). Although it is possible that calves were affected by subclinical disease in the present study, no apparent illness was reported; thus, any connection between health related to restricted milk feeding and variability in postweaning feeding behavior is only speculative. However, evidence suggests that milk feeding level can affect calf health. Immune function is affected by nutrient supply, which is improved in calves that receive more milk (Nonnecke et al., 2003); thus, ADL calves may be at less risk for developing infec- 
tions. It is also possible that SARA may have been a factor influencing daily DMI variability in RES calves. This condition is associated with high intake of rapidly fermentable carbohydrates, such as concentrate (Owens et al., 1998). Provision of forage to calves has been found to improve rumen environment (Coverdale et al., 2004). Thus, increased concentrate intake in RES calves in the absence of a forage source may have resulted in the development of chronic acidosis before weaning. Further research is encouraged to investigate possible associations between milk feeding level, daily variability in feeding behavior, and postweaning health.

Although it is possible that health consequences of early milk feeding level resulted in greater postweaning daily variability in feed intake, it is unclear why day-today variability of most meal characteristics decreased over time across both treatments. The decrease in daily variability of meal characteristics between weeks may simply represent the development of stable behavior patterns, similar to those observed in adult cattle (Melin et al., 2005). It is possible, then, that the greater individual variability in feeding time in RES calves, especially early in the postweaning stage, may be a result of restricted early expression of individual meal patterns due to restricted milk allotment. If individual meal patterns become more stable over time, it is possible that preventing natural meal patterns early in life delays this development.

\section{CONCLUSIONS}

Providing dairy calves with milk ad libitum resulted in more frequent milk meals and more evenly distributed diurnal patterns of milk feeding activity. Calves fed restricted amounts of milk had more frequent, larger solid feed meals before weaning. Milk feeding level had a short-term effect on postweaning feeding behavior, with RES calves having initially greater meal size and rate of intake than ADL calves. Immediately after weaning, calves previously provided restricted amounts of milk also fed more continuously at the time of feed delivery. Calves previously fed restricted amounts of milk had greater day-to-day variability in meal characteristics and intake postweaning. Variability in meal characteristics also decreased over time across treatments. Meal characteristics and diurnal patterns of feeding activity were similar between calves by the end of the study, suggesting that milk feeding level is not a factor contributing to the development of long-term characteristic feeding patterns.

\section{ACKNOWLEDGMENTS}

We thank the staff and students at the University of Guelph, Kemptville Campus Dairy Education and
Research Centre (Kemptville, ON, Canada). In particular, we thank Megan Bruce, Mikayla Baxter, and Julie Fish of the University of Guelph, Kemptville Campus for their technical assistance. Special thanks to Angela Greter and Georgia Mason of the University of Guelph for their insightful comments. This project was funded through a Natural Sciences and Engineering Research Council of Canada (NSERC, Ottawa, ON, Canada) Discovery Grant (T. J. DeVries), an Ontario Ministry of Agriculture, Food and Rural Affairs (OMAFRA, Guelph, ON, Canada)/University of Guelph Production Systems research grant, and support from Nutreco Canada Inc. (Guelph, ON, Canada). This project was also supported through contributions from the Canadian Foundation for Innovation (CFI, Ottawa, ON, Canada) and the Ontario Research Fund (Ministry of Research and Innovation, Toronto, ON, Canada).

\section{REFERENCES}

Albright, J. L. 1993. Feeding behavior of dairy cattle. J. Dairy Sci. $76: 485-498$.

AOAC International. 2000. Official Methods of Analysis. Vol. I. 17th ed. AOAC International, Arlington, VA.

Appleby, M., D. M. Weary, and B. Chua. 2001. Performance and feeding behaviour of calves on ad libitum milk from artificial teats. Appl. Anim. Behav. Sci. 74:191-201.

Arnold, G., and R. Maller. 1977. Effects of nutritional experience in early and adult life on the performance and dietary habits of sheep. Appl. Anim. Ethol. 3:5-26.

Bach, A. 2012. Ruminant Nutrition Symposium: Optimizing Performance of the Offspring: Nourishing and managing the dam and postnatal calf for optimal lactation, reproduction, and immunity. J. Anim. Sci. 90:1835-1845.

Borderas, T. F., A. M. de Passillé, and J. Rushen. 2009. Feeding behavior of calves fed small or large amounts of milk. J. Dairy Sci. 92:2843-2852.

CCAC (Canadian Council on Animal Care). 2009. CCAC Guidelines on the Care and Use of Farm Animals in Research, Teaching and Testing. Canadian Council on Animal Care. Ottawa, ON, Canada.

Chua, B., E. Coenen, J. van Delen, and D. M. Weary. 2002. Effects of pair versus individual housing on the behavior and performance of dairy calves. J. Dairy Sci. 85:360-364.

Coverdale, J. A., H. D. Tyler, J. D. Quigley, and J. A. Brumm. 2004. Effect of various levels of forage and form of diet on rumen development and growth in calves. J. Dairy Sci. 87:2554-2562.

Day, M. L., K. Imakawa, A. C. Clutter, P. L. Wolfe, D. D. Zalesky, M. K. Nielsen, and J. E. Kinder. 1987. Suckling behavior of calves with dams varying in milk production. J. Anim. Sci. 65:12071212.

DeVries, T. J., M. A. G. von Keyserlingk, and K. A. Beauchemin. 2005. Frequency of feed delivery affects the behavior of lactating dairy cows. J. Dairy Sci. 88:3553-3562.

de Passillé, A. M. 2001. Sucking motivation and related problems in calves. Appl. Anim. Behav. Sci. 72:175-187.

De Paula Vieira, A., V. Guesdon, A. M. de Passillé, M. A. G. von Keyserlingk, and D. M. Weary. 2008. Behavioural indicators of hunger in dairy calves. Appl. Anim. Behav. Sci. 109:180-189.

De Paula Vieira, A., M. A. G. von Keyserlingk, and D. M. Weary. 2010. Effects of pair versus single housing on performance and behavior of dairy calves before and after weaning from milk. J. Dairy Sci. 93:3079-3085.

DeVries, T. J., and M. A. G. von Keyserlingk. 2009. Short communication: Feeding method affects the feeding behavior of growing dairy heifers. J. Dairy Sci. 92:1161-1168. 
DeVries, T. J., M. A. G. von Keyserlingk, and K. A. Beauchemin. 2003a. Short communication: Diurnal feeding pattern of lactating dairy cows. J. Dairy Sci. 86:4079-4082.

DeVries, T. J., M. A. G. von Keyserlingk, D. M. Weary, and K. A. Beauchemin. 2003b. Measuring the feeding behavior of lactating dairy cows in early to peak lactation. J. Dairy Sci. 86:3354-3361.

Forbes, J. M. 2007. Voluntary Food Intake and Diet Selection in Farm Animals. 2nd ed. CABI, Cambridge, MA.

Friend, T. H., and C. E. Polan. 1974. Social rank, feeding behavior, and free stall utilization by dairy cattle. J. Dairy Sci. 57:1214-1220.

Friggens, N. C., B. L. Nielsen, I. Kyriazakis, B. J. Tolkamp, and G. C. Emmans. 1998. Effects of feed composition and stage of lactation on the short-term feeding behavior of dairy cows. J. Dairy Sci. 81:3268-3277.

Haley, D. B., J. Rushen, I. J. Duncan, T. M. Widowski, and A. M. De Passillé. 1998. Effects of resistance to milk flow and the provision of hay on nonnutritive sucking by dairy calves. J. Dairy Sci. $81: 2165-2172$.

Hammon, H. M., G. Schiessler, A. Nussbaum, and J. W. Blum. 2002. Feed intake patterns, growth performance, and metabolic and endocrine traits in calves fed unlimited amounts of colostrum and milk by automate, starting in the neonatal period. J. Dairy Sci. 85:3352-3362

Hepola, H. P., L. T. Hänninen, S. M. Raussi, P. A. Pursiainen, A.-M. Aarnikoivu, and H. S. Saloniemi. 2008. Effects of providing water from a bucket or a nipple on the performance and behavior of calves fed ad libitum volumes of acidified milk replacer. J. Dairy Sci. 91:1486-1496.

Herskin, M. S., F. Skjøth, and M. B. Jensen. 2010. Effects of hunger level and tube diameter on the feeding behavior of teat-fed dairy calves. J. Dairy Sci. 93:2053-2059.

Jasper, J., and D. M. Weary. 2002. Effects of ad libitum milk intake on dairy calves. J. Dairy Sci. 85:3054-3058.

Jensen, M. B. 2006. Computer-controlled milk feeding of group-housed calves: The effect of milk allowance and weaning type. J. Dairy Sci. 89:201-206.

Jensen, M. B. 2009. Short communication: Milk meal pattern of dairy calves is affected by computer-controlled milk feeder set-up. J. Dairy Sci. 92:2906-2910.

Jensen, M. B., and L. Holm. 2003. The effect of milk flow rate and milk allowance on feeding related behaviour in dairy calves fed by computer controlled milk feeders. Appl. Anim. Behav. Sci. $82: 87-100$

Jorgensen, K. F., J. Sehested, and M. Vestergaard. 2007. Effect of starch level and straw intake on animal performance, rumen wall characteristics and liver abscesses in intensively fed Friesian bulls. Animal 1:797-803.

Khan, M. A., H. J. Lee, W. S. Lee, H. S. Kim, S. B. Kim, K. S. Ki, J. K. Ha, H. G. Lee, and Y. J. Choi. 2007. Pre- and postweaning performance of Holstein female calves fed milk through step-down and conventional methods. J. Dairy Sci. 90:876-885.

Khan, M. A., D. M. Weary, and M. A. G. von Keyserlingk. 2011. Invited review: Effects of milk ration on solid feed intake, weaning, and performance in dairy heifers. J. Dairy Sci. 94:1071-1081.

Krause, K., and G. Oetzel. 2006. Understanding and preventing subacute ruminal acidosis in dairy herds: A review. Anim. Feed Sci. Technol. 126:215-236.

MacDonald, P. D. M., and P. E. J. Green. 1988. User's Guide to Program MIX: An interactive program for fitting mixtures of distributions. Release 2.3, January 1988. Ichthus Data Systems, Hamilton, Ontario, Canada.

Melin, M., H. Wiktorsson, and L. Norell. 2005. Analysis of feeding and drinking patterns of dairy cows in two cow traffic situations in automatic milking systems. J. Dairy Sci. 88:71-85.
Miller-Cushon, E. K., and T. J. DeVries. 2011. Technical note: Validation of methodology for characterization of feeding behavior in dairy calves. J. Dairy Sci. 94:6103-6110.

Nielsen, B. L. 1999. On the interpretation of feeding behaviour measures and the use of feeding rate as an indicator of social constraint. Appl. Anim. Behav. Sci. 63:79-91.

Nonnecke, B. J., M. R. Foote, J. M. Smith, B. A. Pesch, and M. E. Van Amburgh. 2003. Composition and functional capacity of blood mononuclear leukocyte populations from neonatal calves on standard and intensified milk replacer diets. J. Dairy Sci. $86: 3592-3604$.

NRC. 2001. Nutrient Requirements of Dairy Cattle. 7th rev. ed. Natl. Acad. Sci., Washington, DC.

Odde, K. G., G. H. Kiracofe, and R. R. Schalles. 1985. Suckling behavior in range beef calves. J. Anim. Sci. 61:307-309.

Owens, F. N., D. S. Secrist, W. J. Hill, and D. R. Gill. 1998. Acidosis in cattle: A review. J. Anim. Sci. 76:275-286.

Phillips, C. J. C. 2004. The effects of forage provision and group size on the behavior of calves. J. Dairy Sci. 87:1380-1388.

Pritchard, R. H., and K. W. Bruns. 2003. Controlling variation in feed intake through bunk management. J. Anim. Sci. 81(Suppl. 2):E133-E138.

Provenza, F. D., and D. F. Balph. 1987. Diet learning by domestic ruminants: Theory, evidence and practical implications. Appl. Anim. Behav. Sci. 18:211-232.

Reinhardt, V., and A. Reinhardt. 1981. Natural sucking performance and age of weaning in zebu cattle (Bos indicus). J. Agric. Sci. 96:309-312.

Rushen, J., and A. M. de Passillé. 1995. The motivation of non-nutritive sucking in calves, Bos taurus. Anim. Behav. 49:1503-1510.

Senn, M., S. Gross-Lüem, H. Leuenberger, and W. Langhans. 2000. Meal patterns and meal-induced metabolic changes in calves fed milk ad lib. Physiol. Behav. 70:189-195.

Simitzis, P. E., J. A. Bizelis, S. G. Deligeorgis, and K. Feggeros. 2008. Effect of early dietary experiences on the development of feeding preferences in semi-intensive sheep farming systems - A brief note. Appl. Anim. Behav. Sci. 111:391-395.

Squibb, R. C., F. D. Provenza, and D. F. Balph. 1990. Effect of age of exposure on consumption of a shrub by sheep. J. Anim. Sci. 68:987-997.

Stanton, A. L., D. F. Kelton, S. J. LeBlanc, J. Vormuth, L. K. Fox, and K. E. Leslie. Effect of Tulathromycin on disease and growth in heifers. J. Am. Vet. Med. Assoc. (in press).

Van Soest, P. J., J. B. Robertson, and B. A. Lewis. 1991. Methods for dietary fiber, neutral detergent fiber and nonstarch polysaccharide in relation to animal nutrition. J. Dairy Sci. 74:3583-3597.

Vasilatos, R., and P. J. Wangsness. 1980. Feeding behavior of lactating dairy cows as measured by time-lapse photography. J. Dairy Sci. 63:412-416.

Vasseur, E., F. Borderas, R. I. Cue, D. Lefebvre, D. Pellerin, J. Rushen, K. M. Wade, and A. M. de Passillé. 2010. A survey of dairy calf management practices in Canada that affect animal welfare. J. Dairy Sci. 93:1307-1315.

Vitale, A. F., M. Tenucci, M. Papini, and S. Lovari. 1986. Social behaviour of the calves of semi-wild Maremma cattle, Bos primigenius taurus. Appl. Anim. Behav. Sci. 16:217-231.

von Keyserlingk, M. A. G., L. Brusius, and D. M. Weary. 2004. Competition for teats and feeding behavior by group-housed dairy calves. J. Dairy Sci. 87:4190-4194.

Weingarten, H. P. 1983. Conditioned cues elicit feeding in sated rats: A role for learning in meal initiation. Science 220:431-433. 